\title{
Time allocation in a museum: an empirical investigation
}

\author{
Juan Gabriel Brida ${ }^{1 *}$, Marta Meleddu², Manuela Pulina ${ }^{3}$ and Vania Statzu ${ }^{4}$
}

Received: 25/10/2013 Accepted: 30/10/2013

\footnotetext{
${ }^{1}$ School of Economics and Management - Free University of Bolzano. Piazza dell'Università, 39100 Bolzano, Italy.JuanGabriel.Brida@unibz.it

2 Department of Economics and Business (DiSEA) \& CRENoS, University of Sassari, Via Torre Tonda, 34, 07100 Sassari, Italy, E-mail: mmeleddu@uniss.it

${ }^{3}$ Department of Economics and Business (DiSEA) \& CRENoS, University of Sassari, Via Torre Tonda, 34, 07100 Sassari, Italy, E-mail: mpulina@uniss.it

${ }^{4}$ CRENoS and Dipartimento di Scienze Sociali ed Istituzioni - Università di Cagliari, via San Giorgio 12, 09124 Cagliari-Italy E-mail: vania.statzu@crenos.unica.it.

*

Corresponding author
}

\begin{abstract}
This paper examines the determinants that influence the time spent by visitors in a cultural site. This empirical investigation is based on survey data collected at the South Tyrol's Museum of Archaeology in Bolzano (Italy) between June and August 2010. Descriptive statistics show that, on average, visitors spend almost two hours, much longer than the length of stay in other museums as found in former empirical studies. Empirically, a zero-truncated Negative Binomial model has proved to achieve the best results. The analysis reveals that gender, age, income, group type, time spent at the destination, importance attributed to the museum and weather conditions have an impact on length of stay at this cultural site. These findings provide a useful tool to implement management directions about the museum.
\end{abstract}

(C) 2014 International University College. All rights reserved

Keywords: time; museum; zero-truncated Poisson; management implications.

Citation: Brida, J., M. Meleddu, M. Pulina and V. Statzu (2014) Time allocation in a museum: an empirical investigation. European Journal of Tourism Research 7, pp. 5-15

\section{Introduction}

Many studies have been devoted to explain the factors that influence visitors' expenditure pattern and time spent in recreational and cultural sites (see Frey and Meyer 2003; Brida et al. 2012 for an updated review). However, the aim of examining the factors influencing the time spent in a museum have considerably changed over time. In the great part of the previous studies, the amount of time spent in a museum by visitors was regarded as an indicator of learning, although studies on the educational role of informal setting such as museums and exhibitions are still quite numerous in the literature (see Adams et al. 2010 for an extensive review). Such a strand of literature links to the main definition of museums. As provided by the International Council of Museums (ICOM 2007), a museum is as "a non-profit, permanent institution in the 
service of society and its development, open to the public, which acquires, conserves, researches, communicates and exhibits the tangible and intangible heritage of humanity and its environment for the purposes of education, study and enjoyment".

This paper explores in a more systematic manner the factors that influence the allocation of time by visitors at a cultural site. To this aim, as an economic indicator, time spent at a museum is employed. As a case study, visitors' experience to the South Tyrol's Museum of Archaeology in Bolzano (Italy) is analysed. This museum is known as "Ötzi", as it hosts a unique glacial mummy dated more than 5000 years ago discovered recently in the Alps (Schnal Valley Glacier), together with his accompanying artefacts (clothing and equipment). Hence, this museum has a special interest for its authenticity and uniqueness, fundamental characteristics for such type of cultural attractions.

Based on a sound theoretical model, empirically, a zero-truncated negative binomial model is estimated to understand in what extent a set of factors affect the time spent at the site. The findings provide useful information for the Ötzi museum managers, giving insight on how much this cultural attraction is appealing to visitors and how better exploit this ancient discovery. Furthermore, the results may be used to help promoting better marketing strategies that can improve the overall educational mission of this museum.

The paper is organised as follows. In the following section, a literature review is provided. In Section 3, the methodological framework is addressed. Section 4 provides a description of the case study and of the administrated questionnaire. In Section 5, the empirical results are presented. The last section provides concluding remarks.

\section{Literature review}

There are a numerous studies that investigate visitors' learning and educational experience at cultural attractions. In this sense, Falk (1983) finds that observable behavior and time spent at a cultural site are strong predictors of learning, nevertheless neither time nor behavior by itself can be regarded as a perfect measure in predicting the actual learning process. Specifically, the author finds that those children who spent a reasonable length of time at the exhibit, and showed a positive behavior in the process, had significant changes in their scores from the pre-test to post-test. Sandifer (1997) seeks to understand whether time-based learning-associated visitors' behavior, at interactive science museums, differ across weekend/weekday groups and family/non-family groups. Results show that regardless of the day of the visit, overall families spent more time than nonfamilies in individual exhibitions and in the science museum; however, weekend family and non-family visitors did not differ much in their average time spent per exhibit. These results are explained by a difference in visitors' agenda and the crowded nature of weekend visits.

Other studies are devoted to understand visitors' behavior during an exhibition visit. In an extensive work, Serrell (1997) concludes that, during their visit at the museum exhibition, people plan to find a personal path, often skipping many elements or visiting only a part of it. Generally, time spent at exhibitions is rather short, approximately 20 minutes, and people spend less time per unit area in larger exhibitions and diorama halls than in smaller or non-diorama exhibitions. Sandifer (2003) analyses how different characteristics of exhibitions influence the total time spent in a museum. He finds that the characteristics of technological novelty and open-endedness explain the variance in the amount of time that exhibits hold visitors' attention. The technological novelty result is a quite common outcome. This strand of research established that visitors tend to spend more time at exhibits showing novel phenomena or objects, in part because novelty is an important factor as in intrinsic motivation and task engagement. Hence, a recent literature is devoted to understand the influence of technology in time spent at a museum. Sung et al. (2008) find that visitors with electronic guidebooks had a longer holding time at exhibits than the visitors without supplementary materials. Moreover, a large portion of the variance in average holding time remains unexplained. The author suggests to 
improve next studies inserting variables, such as prior knowledge of the exhibit content, interest in exhibit content, and visitor perception of the exhibit, to reduce the unexplained variance.

Kraaykamp et al. (2008), within an extensive literature review, analyse the role of the time constraint in cultural participation, showing that there has been a lack of interest in time constraint in the literature about cultural participation determinants. They highlight that previous studies show only modest effects of time constraints but most studies have used individual time budgets, thereby neglecting the social relationship of individuals within the family. They start from the assumption that cultural participation is not similar to other spare time activities, but it is linked to a previous knowledge of the theme of the exhibition. Hence, more educated people are more likely to visit cultural events than those with a lower education, although knowledge that positively influences the amount of time spent at exhibition can be also transmitted through relationships. To this respect, different studies show that parental schooling levels and family socialisation, level and type of education and cultural preferences as well as background characteristics of the spouse affect cultural participation.

As a further topic in the literature, length of stay at a cultural site is regarded as a satisfaction indicator. One critical, but usually disregarded, characteristic of a museum is that the visit is an experience good. An experience good is a product or service where the product characteristics, such as its quality, is difficult to observe in advance, but these characteristics can only be ascertained upon consumption. Frey and Steiner (2010) provide an extensive revision of the literature on charging practices in museums. They find that a pay-as-you-go policy will be the most efficient charging practice and they propose the application of exit prices. The longer time is spent in a museum, the higher is the exit price, that is those staying longer have profited more and may find it fair to pay more than somebody staying only for a shorter span of time. In the presence of entry fees the individual only has to calculate the opportunity cost of his/her time as the price does not depend on how long the visit is. Exit prices have the major advantage that takes into account how satisfied the visitors were with the museum. Efficiency is raised because visitors pay according to their utility maximization, measured as length of stay in the museum. As a side effect of being more satisfied, visitors may be willing to spend more money at the museum shop and restaurant.

On the whole, to increase visitors' length of stay, museums have broadened the range of services they provide as well as the variety of collections and exhibits. There are four main types of services: physical comfort and accessibility (well-designed galleries, lighted and safe parking lots, ramps, seating and rest areas, clean restrooms, etc.); hospitality (welcoming behaviour on the part of guides, guards, and other employees); interpretive, narrative, and way-finding information (including the use of different media) that increase a visitor's awareness and knowledge; recreation and diversion, including shops and dining facilities. Museums are providing a greater variety of facilities, such as library and electronic-learning tools, folding chairs for the galleries, specialty gift shops and family activity areas and rest stops (Kotler, 1999). Web sites and other internet facilities that improve knowledge of the exhibition before the visit and the possibility to have personalized on-site tours (e.g. Wang, 2009). Nowadays, museums have to help visitors to develop skills through a learning process and a more participated and autonomous role (Rounds, 2004).

Governments and policy makers also see museums as a source of revenue. A strand of the literature that explores the relationship between museums and its economic impact (Choi et al., 2010; Kinghorn and Willis, 2007; Scott, 2009) revealing that museums have significant multiplier effects into the local economy, in terms of higher income and employment. Overall, from the literature review it emerges that less studies have been devoted to understand visitors' behaviour during their stay in a museum and its determinants from an economic perspective. In capitalist societies, museums represent both a cultural attraction and a consumption experience, often able to raise the wealth of the hosting community. 
Cultural participation is not often free and several studies have examined the pricing rules for entry fees. For example, Lampi and Orth (2009) assess the effect of the introduction of an entrance fee on the Museum of World Culture in Sweden. They show that visitors who regularly visit cultural attractions are willing to visit the museum regardless of the fee level. However, four out of the six target groups declare to be less likely to visit the museum after the implementation of the fee. They show that the composition of museum visitors, which was not evenly distributed across different socio-economic groups during the free entrance period, became even more skewed after the introduction of the fee. Economic turmoil, as experienced in the past decade, can reduce both private and public funding, hence museums thanks to their revenues are still able to provide a wide range of attractions and invest in more advanced technologies to appeal to broad based tastes (Tufts and Milne, 1999).

From the reviewed studies, it also emerges that income positively influences cultural participation but also occupational class is find to be an important predictor of time spent visiting exhibitions. Time pressure and financial resources are found to be related in most studies. Full-time working couples generally have more financial resources, but also are under more time pressure since they participate more in paid labour. As a result, part of the relationship between full-time working couples and cultural participation is interpreted through the abundant financial assets enjoyed by full-time workers.

The present paper investigates the determinants that influence visitors' time allocation to a museum, underpinned to sound microeconomic foundations.

\section{Model specification}

Theoretically, the present empirical research is underpinned to the consumer behaviour theory developed by Lancaster (1966) and Rosen (1974). Goods characteristics are the source of consumer's utility whose final aim is its maximisation in terms of prices and quantities of characteristics. Considering a specific site (i.e. a museum), several elements contribute to determine consumer's choice, as highlighted by the literature review. Indeed, every site incorporates a bundle of characteristics and perceived features that will determine the utility of each consumer.

A fundamental role in this sense is played by the time spent at a site that is influenced by the budget that visitors allocate to the visit and upon their preferences. A visitor chooses to consume a bundle of goods $x$ according to his/her characteristics, subject to an income constraint $M$, and considering the prices of the purchased good $\left(p\left(x_{1}, x_{2}, \ldots ., x_{c}\right)\right)$ and the other goods $(d)$, as follows:

$\operatorname{Max} U\left(x_{1}, x_{2}, \ldots, x_{c}\right)$ subject to

$p\left(x_{1}, x_{2}, \ldots, x_{c}\right)+d=M$

When choosing a cultural site to visit the consumer chooses the typology he/she prefers along with the time to allocate to the visit. The demand function expressed in terms of time spent at the site can be formulated in the following manner:

$T_{j}=\left(x_{j}, p_{j}, Y, \eta_{i}, \varepsilon_{j}\right)$

where, the visitor will stay in a given cultural site $j$ according to the site characteristics $x_{j}$, prices $p_{j}$, income $Y$, individual non observable characteristics $\eta_{i}$ and site non-observable characteristics $\varepsilon_{j}$. As visitors do not share the same set of factors in their utility function, it is important to account for heterogeneity in a way to take into consideration those who may prefer shorter stays (Alegre et al., 2011).

Empirically, the methodological procedure consists of running an initial standard Poisson, as a restriction of the more general Negative Binomial distribution, specified in the following manner:

$$
\begin{aligned}
& \operatorname{Prob}\left(Y_{i}=y \mid w\right)=\frac{e^{-\lambda} \lambda^{y}}{y !} \\
& E\left(y_{i} \mid w_{i}\right)=\operatorname{Var}\left(y_{i} \mid w_{i}\right)=\lambda=e^{x_{i}^{\prime} \beta}
\end{aligned}
$$

where the random variable $y$ follows a Poisson distribution; the parameter $\lambda$ represents both the average and the variance of the Poisson 
distribution; $w_{i}$ denotes the other controls (e.g. socio-economic characteristics of individual $i$, perception of the bundle of characteristics of the destination and costs). As the Poisson model is non-linear the maximum likelihood technique is used.

In the literature, there appear many extensions of the Poisson model according to the characteristics of the empirical data as well as because of the stringent condition of the mean equal to the variance (Greene, 2003). In the present empirical study, the exact time spent at the site is assessed for each individual, avoiding the right censoring problem (i.e. observation period ends before the event has taken place). This is possible since all visitors at the site are asked about their time spent at the museum. The variable cannot assume negative values and ranges from one to $N$, and therefore is zero-truncated. In other words, a record would not appear in the database if a visitor had not spent at least a few minutes at the museum. In this case, the distribution includes either a zero-truncated Poisson or a zero-truncated Negative Binomial. The former is a restriction of the more general Negative Binomial specification and is given by the following expression:

$$
\operatorname{Prob}\left(Y_{i}=y \mid y>0\right)=F_{T P}(y)=\frac{e^{-\lambda} \lambda^{y}}{Y !}\left[1-F_{P}(0)\right]^{-1}
$$

where $F_{T P}$ is the distribution of the zerotruncated Poisson.

The variance equal to the mean is a strong assumption, that when not satisfied leads to the more general specification. A Negative Binomial Model can in fact be constructed allowing for over-dispersion that occurs when only a few individuals had a large number of hours spent at the museum, implying the variance in visits is larger than the mean. This model is specified by the following equation: where $F_{T N B}$ is the density function of the zerotruncated Negative Binomial distribution, $\vartheta$ is an ancillary parameter to be estimated from the data, $\Gamma$ is the gamma function and $F_{P}$ is the density function of the Poisson distribution. The estimation is run using maximum likelihood (Menezes et al., 2010).

\section{The case study and the survey}

\section{Ötzi the ice-mummy}

The principal attraction of the city of BolzanoBozen, in the North-East of Italy, is the Archaeological museum, opened on March 1998, situated in the city centre. The museum is approximately 1200 sq. m. and hosts an exhibition on the prehistorically period in South Tyrol, although the main mission of the museum is to host and preserve one of the world's most important mummies, Ötzi the Iceman, a mummy well preserved for 5300 years. Hence, visitors can somehow decide their visiting path along the exhibition rooms and decide if he/she wants to view the mummy. All the sections devoted to the "Iceman" are characterised by a sober and scientific atmosphere, in order to promote both scientific research and cultural insight related to the man from the Chalcolithic Period. Almost two decades after the Iceman's discovery, this mummy is the object of an intense research by biologists, anthropologists, pathologists who can still unravel mysteries by employing more advanced and new-generation equipment.

Other than the mummy itself, visitors can also admire and revive this mummy's times thanks to his unique artefacts exhibition. The ice man carried a numerous possessions: his axe with a copper blade denotes Ötzi prestigious status in society and is the only completely intact prehistoric axe ever found; also his shoes represent an extraordinary finding, a unique example of this kind from the past, made of warm hay in the inner part while of deerskin on the outside; his leggings were practical and functional, and quite similar to those still used

$$
\operatorname{Prob}\left(Y_{i}=y \mid y>0\right)=F_{T N B}(y)=\frac{\Gamma\left(Y+\frac{1}{\vartheta}\right)}{\Gamma(Y+1) \Gamma\left(\frac{1}{\vartheta}\right)}\left(\vartheta \lambda_{I}\right)^{Y}\left[1+\vartheta \lambda_{I}\right]^{-\left(Y+\frac{1}{9}\right)}\left[1-F_{P}(0)\right]^{-1}
$$


by native North Americans in the $19^{\text {th }}$ century; his hunting and self-defence equipment comprise a flint-bladed dagger and arrows; his survive kit consists of flesh of birch fungus possibly used as an antibiotic to fight infections and a variety of medical conditions (Fleckinger, 2007). From a financial point of view, the museum has revenues from merchandising, sponsors and from tickets sales. Since its opening, it had around 250,000 visitors per year. The museum kindly provided the authors data on visitors' flows from 2007:1 to 2010:12. A graphical representation of the moving trend proposed by Hodrick and Prescott (1997; calculated using Eviews 5.0) helps identifying the general trend of series, as shown in Figure 1. A relatively moderate trend characterises visits to the museum. Overall, the seasonal distribution for the actual visits depicts a unimodal shape with a maximum peak in August. On average, the museum hosted around 18000 visitors per month.

\section{The survey}

To explore the determinants influencing the length of stay at the museum, a survey was administered at the site, from June to August 2010, via face-to-face interviews on weekdays (except for the closing day on Mondays) and on Saturdays and Sundays, at different opening hours (between $10.00 \mathrm{am}-6.00 \mathrm{pm}$ ). Sergardi and Biraghi (2007), for Italy, found that cultural seasonal distribution is very stable during the year (from a minimum of $25 \%$ to a maximum of $31 \%$ ), nevertheless, the highest flows of touristvisitors occur between June and August. Hence, running the survey within such a span of time can provide better insight on the heterogeneous characteristics of visitors.

The respondents were selected with a quota random sampling procedure based on age and gender trying to capture heterogeneous demographics features. As opposed to random sampling, quota sampling requires that representative respondents are chosen out a subset of individuals within a population. Notwithstanding this procedure may lead to bias because not everyone gets a chance to be selected, nevertheless, it overcomes the potential bias derived from a random sample procedure, as the trial may be likely to over-

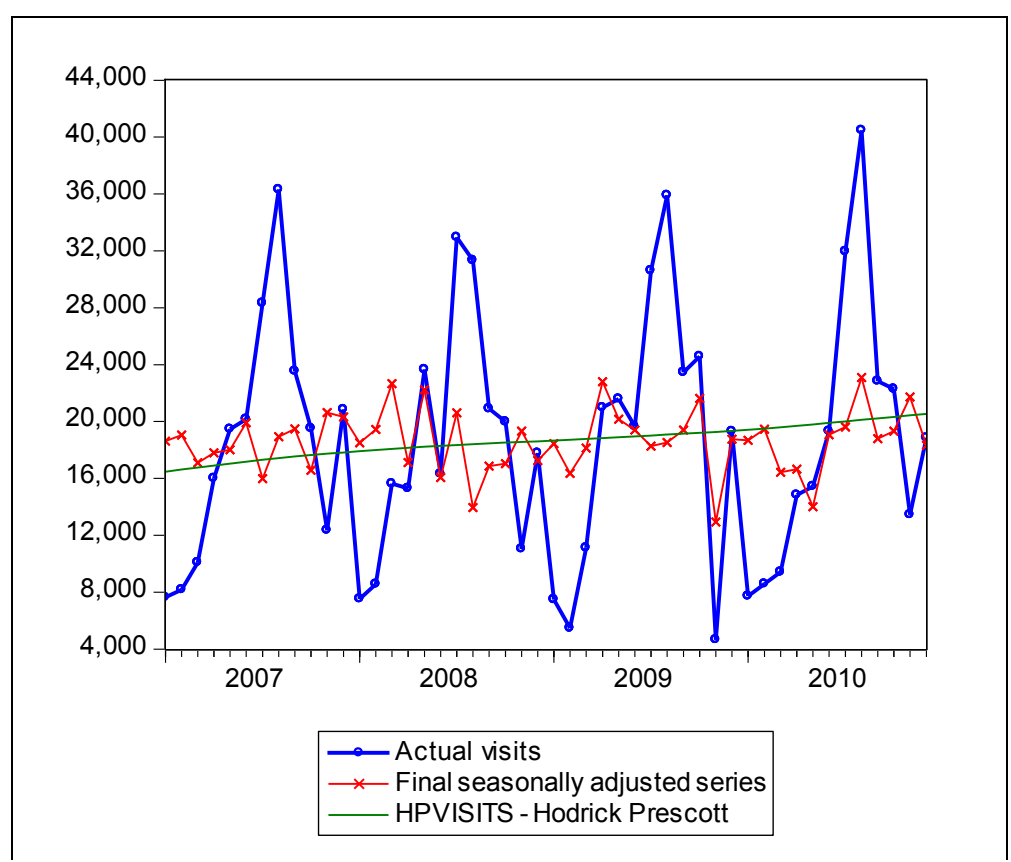

Figure 1. Actual visits to the museum; final seasonally adjusted series; Hodrick-Prescott Filter 
represent specific demographic characteristics, such as gender or age. Based on visitors' data of the previous year, provided by the administrative office of the museum, the sample size was determined according to a $95 \%$ confidence level with a 5\% error. Overall, 724 complete interviews were successfully concluded.

In total, the questionnaire contained 36 questions, organized in four blocks: the first section asked trip information, the next demanded information about the city of Bolzano, then information on the visit to the museum are collected and, as the last section, a sequence of questions on socio-economics characteristics of the visitors. In the questions on how important is to visit Bolzano and the museum, information, motivation, satisfaction and loyalty a Likert scale was used ranging from 'not important' to 'very important' for the motivation factors, from 'strongly in disagree' to 'strongly in agree' for assessing tourist's satisfaction, and from 'very unlikely' to 'very likely' for the loyalty factors. Table 1 provides main descriptive statistics to give a better picture of visitors of the Archaeological Museum and Bolzano.

Table 1. Descriptive statistics

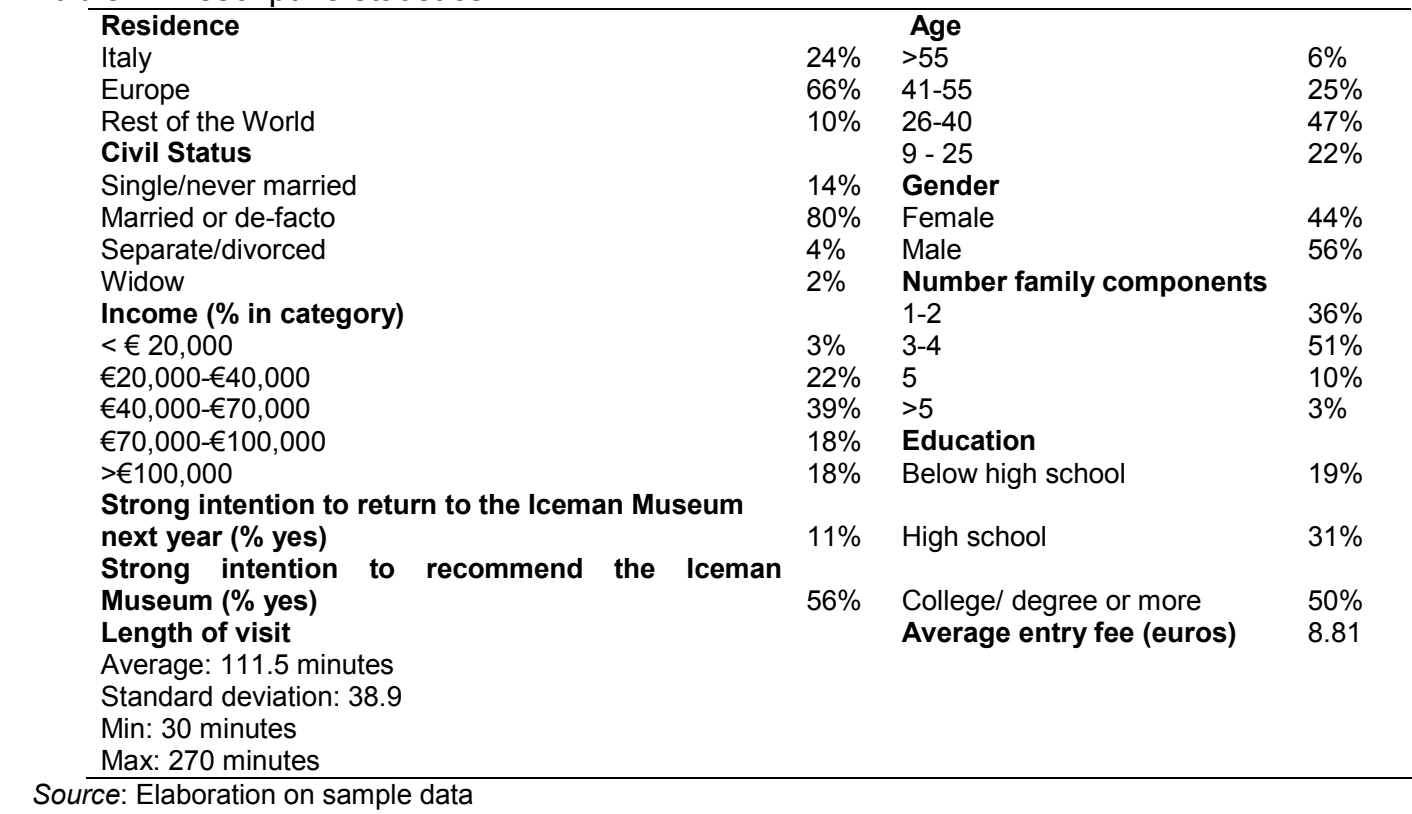

Most of the visitors (66\%) came from other European countries rather than Italy (24\%). Responders are mostly male (56\%), generally married or de-facto (80\%), with a family of 3-4 members $(51 \%)$; those between 41 and 55 years old are more interested in the museum visitation (47\%) if compared to other age range. Regarding the education level, $50 \%$ had a college degree or a higher degree. Moreover, $39 \%$ of the sample had a middle-high average income, while just 3\% less than 20000 euros per year. $11 \%$ expressed a strong intention to revisit the museum the following year, while $56 \%$ declared that they will very likely advise relatives and friends to visit this museum. The average entrance fee was 8.81 euros and the average time spent visiting the museum was 111.5 minutes, hence almost two hours. Interestingly, the minimum time spent on the visit was half an hour, whereas the maximum was four hours and half. This is an important result as reported by Serrell (1997) time spent at exhibitions is approximately 20 minutes since visitors, during their visit tend to follow a personal path, often visiting only a part of the exhibition.

\section{Econometric results}

The empirical estimation is based upon the 
Table 2. List of variables

\begin{tabular}{|c|c|}
\hline Name & Definition \\
\hline \multicolumn{2}{|l|}{ Dependent variable } \\
\hline Length of visit & Total minutes spent at visiting the museum \\
\hline Explanatory variables & \\
\hline Gender & Dummy: one if male; zero otherwise \\
\hline Age-Ages & Age of the respondent, as a continuous variable - and its square \\
\hline Italian & Dummy: one if Italians; zero otherwise \\
\hline Organized group & Dummy: one if respondent travels within an organized group; zero otherwise \\
\hline $\begin{array}{l}\text { Length of stay in South } \\
\text { Tyrol }\end{array}$ & $\begin{array}{l}\text { Number of nights spent in South Tyrol, away from visitor's actual place of } \\
\text { residence }\end{array}$ \\
\hline Importance museum & $\begin{array}{l}\text { Discrete variable that takes values from } 1 \text { (not important at all) up to } 5 \text { (very } \\
\text { important) attributing an increasing importance to visiting the Museum. }\end{array}$ \\
\hline Bad weather & $\begin{array}{l}\text { Discrete variable that takes values from } 1 \text { (not important at all) up to } 5 \text { (very } \\
\text { important) attributing an increasing importance for visiting the Archaeological } \\
\text { Museum during bad weather conditions. }\end{array}$ \\
\hline Family income & Number of household's members who have an income \\
\hline Ticket & $\begin{array}{l}\text { Price paid by the respondent to visit the Archaeological Museum of South } \\
\text { Tyrol }\end{array}$ \\
\hline Entrance fee & Price paid by the respondent for his/her own group to visit the Museum \\
\hline
\end{tabular}

Table 3. Zero-truncated Poisson (ZTP) versus Zero-Truncated Negative Binomial (ZTNB): regression results

\begin{tabular}{lrr}
\hline Variables & ZTP - IRR & ZTNB - IRR \\
\hline Italian (reference group other & $1.028(0.039)$ & $1.036(0.039)$ \\
nationality) & $0.923(0.031)^{* *}$ & $0.931(0.031)^{\star *}$ \\
Gender (ref. female) & $0.994(0.004)$ & $0.995(0.004)$ \\
Age & $1.000(0.000)^{\star *}$ & $1.000(0.000)^{\star *}$ \\
Ages & $0.815(0.071)^{\star *}$ & $0.815(0.071)^{\star *}$ \\
Organized group & $0.951(0.027)^{\star}$ & $0.947(0.027)^{\star}$ \\
Nfamincome & $1.000(0.003)^{\star \star *}$ & $1.012(0.003)^{\star * *}$ \\
Length of stay in South Tyrol & $1.100(0.019)^{\star * *}$ & $1.094(0.019)^{\star * *}$ \\
Importance visit Ötzi & $1.044(0.015)^{\star * *}$ & $1.042(0.014)^{\star * *}$ \\
Bad weather & $0.999(0.001)$ & $0.999(0.001)$ \\
Entrance fee & 0.1368 & 0.0209 \\
Pseudo R ${ }^{2}$ & 88.90 & 81.65 \\
Wald chi2(10) & Prob> $\chi 2=0.000$ & Prob> $\chi 2=0.000$ \\
Log pseudolikelihood & -3331.0016 & -1841.6687 \\
AIC & 6684.00 & 3707.34 \\
BIC & 6727.02 & 3754.27 \\
\hline
\end{tabular}

Notes: ${ }^{* * *},{ }^{* *}$ and * indicate statistically significance at the $1 \%, 5 \%$ and $10 \%$ level, respectively; IRR indicate the exponentiated coefficients $=\mathrm{e}^{\wedge} \mathrm{b}$; Robust Standard Errors are in parenthesis.

theoretical framework specified in Section 3. The relevant variables included into the model, and obtained by the survey data, are described in detail in Table 2.

The best specification has been identified as a zero-truncated Negative Binomial (ZTNB) and Table 3 provides a comparative analysis with respect to the zero-truncated Poisson (ZTP), as the restricted specification. The estimation is run by using STATA 10 and results are reported on IRR (incidence rate ratio).

The dependent variable, length of stay at the museum $(L)$ ranges from one to $N$ (i.e. the count variable cannot be zero), given the definition provided in the theoretical specification. The goodness-of-fit test in the standard Poisson model suggests that the null hypothesis (i.e. the empirical model fits the 
data) cannot be accepted (i.e. Goodness-of-fit $\chi 2=4260.66-$ Prob $>\chi 2(358)=0.0000)$. Hence, a negative binomial needs to be estimated.

As a further step, a comparison is done between the zero-truncated Poisson (ZTP) and the ZTNB, via the information criteria, where the Akaike information $(A / C)$ is 6684.00 and 3707.34 , respectively, and the Bayesian information (BIC) is 6727.02 and 3754.27 , respectively. In the latter case they are minimised. Furthermore, the Likelihood-ratio test of alpha (chibar2 $=2978.67$ Prob $>=$ chibar2 $=0.000$ ) assesses the empirical validity of the ZTNB, as the null of variance equal to the mean, and hence, no over-dispersion, fails to be accepted. Besides, the Wald test for the ZTNB indicates that the overall model is well specified at the level of significance of $1 \%$ (Wald test $\left.\chi^{2}=81.65\right)$. Hence, there is statistical ground to retain the ZTNB as a better empirical specification. The model has been estimated correcting for robust standard errors, given the relatively low number of observations may lead to heteroschedasticity problems in the residuals. Notably from Table 3 , it emerges that ZTP and ZTNB results show rather marginal differences.

Taking into account statistically significant coefficients (at least at the 10\% level of significance), amongst the variables of interest, ceteris paribus, male, youngsters and respondents belonging to organised groups denote a lower probability to stay longer at the museum. Overall family income also plays a role in the time spent at the site: the results show that higher respondents' family members having an income, the lower the time allocated to the visit. This is may be consistent with the results achieved by previous studies where it is assessed that visitors with full-time jobs have less spare time to dedicate to cultural attractions, particularly if they are male.

The higher is the length of stay in the South Tyrol the more likely to spend a longer span of time visiting the museum. One may argue that tourists visiting the destination, for other recreational purposes, during the summer peak, may be attracted by this unique cultural attraction. The time spent at the site is also positively influenced by the importance respondents attribute to the museum itself, as well as by the adverse weather conditions. Interestingly, the entrance fees (defined as the overall amount spent by the respondent for his/her group) do not affect the allocation of time in the museum. Same result has been achieved when considering the entrance fee per respondent. This result may be congruent with the fact that in this case the average time spent in the museum is relatively high (almost two hours) and the minimum length of stay, as it emerges in other studies, is at least half an hour.

\section{Discussion and conclusions}

This paper has aimed to analyse the determinants that influence visitors' time allocation to a museum, underpinned to sound microeconomic foundations. The case study was the South Tyrol's Museum of Archaeology in Bolzano (Italy), best known as the Ötzi museum. Empirical data were obtained via a survey on 724 visitors at the museum from June to August 2010. Ötzi, and consequentially the Archaeological Museum, is already considered as the main attraction of the city of Bolzano.

To establish the factors that influence the time spent at the museum, a zero-truncated Negative Binomial has been implemented, based upon a microeconomic theoretical framework. From the final restricted specification, empirical results, in line with previous studies, have shown that demographics and economics characteristics are able to predict the length of the visit. Among demographics determinants male, youngsters and respondents belonging to organise groups have denoted a lower probability to stay longer at the museum. Same result has been achieved for respondents belonging to a family with several members having an income. On the opposite, adverse weather conditions, the higher the length of stay in the South Tyrol, the more importance respondents attribute to the museum the more likely is to spend a longer span of time visiting the site.

These findings lead to specific managerial implications useful for museum managers. 
First, the museum may propose a ticket price discrimination offering a different path of visiting, timing and services (e.g. multimedia electronic guides) for each visitor typology, based upon their average length of the visit. For instance, people travelling with an organised group tend to allocate on average 88 minutes. For this typology, a visiting itinerary with services that can guarantee an adequate coverage of the overall exhibition can be implemented. Adapting the experience and the services in the museum to different consumer segments may further enhance visitors' satisfaction.

A marketing campaign can also be done to attract youngsters to the museum, who are likely to spend less time at the site than older people. Museum coupons can be distributed to youngsters to encourage future visits to the museum, at specific time of the day. Especially young children may enjoy the benefit of being guided by trained staff during their visit, increasing the overall satisfaction for the whole family.

From the graphical inspection on the actual visits to the museum, it has emerged that the trend is rather stable in the second half of the past decade (2007-2010). This finding indicates that further management and marketing policies need to be activated to attract new segments of demand. As reported by the local press (Mair 2010; Vikoler 2010), the existing building hosting Ötzi is inadequate for a wider audience (e.g. researchers, academics, locals) and a debate is still on-going around the possibility to transfer the museum to a larger building. So far, a decision has not been taken. Yet, policy makers should closely consider the impact that Ötzi museum has on tourism, on the local community education and on the longterm awareness of society roots. Ötzi can be regarded as a vital stimulus for the local economy as well as a repository of the historical knowledge, but its fruition to a wider audience is still limited, due to the actual building capacity.

The present study can be further expanded to other heritage sites, providing robustness to the present paper. Besides, a future challenge of research in this field will involve investigating residents' perceptions and awareness about the importance of Ötzi and the other archaeological findings for cultural and education purposes. Most importantly, it would be interesting to assess resident's willingnessto-pay to invest in a new building, as a key centre of education and cultural activity, that is able to attract not only occasional demand but also the local community.

\section{Acknowledgement}

Our research was supported by the Free University of Bolzano project, "Heritage, Sustainability and Economic Growth", and by the Autonomous Province of Bolzano project "Le attrazioni culturali e naturali come motore dello sviluppo turistico. Un'analisi del loro impatto economico, sociale e culturale", Research Funds 2009. A preliminary version of this paper was presented at the Economic Seminar of the National University of Colombia in Medellin, August 2012

\section{References}

Adams M., Luke, J. \& Ancelet J. (2010). Family learning in art museum interactive spaces: a literature review. In K. Raney (Ed.) Family learning. London: engage, pp.19-30.

Alegre, J., Mateo, S. \& Pou, L. (2011). A latent class approach to tourists' length of stay. Tourism Management, 32, 555563.

Brida J.G., Meleddu, M. \& Pulina M. (2012). Understanding urban tourism attractiveness: the case of the Archaeological Ötzi Museum in Bolzano. Journal of Travel Research, 51(6), 727-738.

Choi, A. S., Ritchie, B.W. Papandrea, F. \& Bennett J. (2010). Economic valuation of cultural heritage sites: A choice modeling approach. Tourism Management, 31, 213-220.

Falk, J. H. (1983). Time and behavior as predictors of learning. Science Education, 67, 267-276.

Fleckinger, A. (2007) Ötzi, the Iceman. Folio, Vienna/Bolzano.

Frey, B. S. \& Meier S. (2003). The economics of museums. Institute for Empirical Research in Economics, University of Zurich, Working Paper Series No. 149 
Frey, B. S. \& Steiner, L. (2010). Pay as you go: a new proposal for museum pricing. CESIFO Working Paper No. 3045.

Greene, W. (2003). Econometric analysis. $5^{\text {th }}$ ed. Prentice Hall, New Jersey.

Hodrick, Robert, and Edward C. Prescott (1997). Postwar U.S. Business Cycles: An Empirical Investigation, Journal of Money, Credit, and Banking, 29 (1), 116.

ICOM (2007). Museum definition. URL: http://icom.museum/who-we-are / thevision / museum - definition.html (Accessed 10 November 2012).

Kinghorn, N., \& Willis, K. (2007). Estimating visitor preferences for different art gallery layouts using a choice experiment. Museum Management and Curatorship, 221, 43-58.

Kotler, N. (1999). Delivering experience: marketing the museum's full range of assets. Museum News, May/June.

Kraaykamp G., Van Gils, W. \& Ultee W. (2008). Cultural participation and time restrictions. Explaining the frequency of individual and joint cultural visits. Poetics 36, 316-332.

Lampi, E. \& Orth, M. (2009). Who visits the museums? A comparison between stated preferences and observed effects of entrance fees. Kyklos, 62, 85102.

Lancaster, K. J. (1966). A new approach to consumer theory. The Journal of Political Economy 74, 132-157.

Mair, G. (2010). Im Haus gegenüber, FF Südtiroler Wochenmagazin, 39, 40.

Menezes. G.A., Moniz, A. \& Vieira J.C. (2010). The determinants of length of stay in the Azores: A count model approach, CEEAPIA WP No. 03/2010, 1-28.

Rosen, Sherwin. (1974). Hedonic Prices and Implicit Markets: Product Differentiation in Pure Competition. Journal of Political Economy, 82(1), 34-55
Rounds J. (2004). Strategies for the curiositydriven museum visitor. Curator 47, 389410.

Sandifer C. (1997). Time-based behaviors at an interactive science museum: exploring the differences between weekday/weekend and family/nonfamily visitors. Science Education, 81, 689-701.

Sandifer C. (2003). Technological novelty and open-endedness: two characteristics of interactive Exhibits that contribute to the holding of visitor attention in a science museum. Journal of Research in Science Teaching, 40, 121-137.

Scott, C.A. (2009). Exploring the evidence base for museum value. Museum Management and Curatorship, 24, 195212.

Sergardi, P. \& Biraghi A. (2007). Il ruolo del turismo culturale e del turismo d'affari nell'incoming internazionale dell'talia. L'Italia ed il turismo internazionale. Pragma. TNS Infratest.

Serrell B. (1997). Paying attention: the duration and allocation of visitors' time in museum exhibitions. Curator, 40, 108125.

Sung, Y.-T., Chang, K. E., Lee, Y. H. \& Yu W. C. (2008) Effects of a mobile electronic guidebook on visitors' attention and visiting behaviors, Educational Technology \& Society, 11, 67-80.

Tufts, S., \& Milne, Y. (1999). Museums. A supply-side perspective. Annals of Tourism Research, 26, 613-631.

Vikoler, T. (2010). Ötzi im Stadtmuseum. Neue Südtiroler Tageszeitung, 11.

Wang, Y., Aroyo, L., Stash, N., Sambeek, R., Schuurmans, Y., Schreiber, G. \& Gorgels, P. (2009). Cultivating personalized museum tours online and on-site. Interdisciplinary Science Reviews, 34, 141-156. 